\title{
Wheel Dynamic Response to Rolling Excitation on Road
}

\author{
Weiji Wang ${ }^{1, a^{*}}$ \\ 1Department of Engineering and Design, University of Sussex, Brighton BN1 9QT, United Kingdom \\ aw.j.wang@sussex.ac.uk
}

Keywords: Wheel structural dynamics, Noise reduction, Damping

\begin{abstract}
In this paper, tyred wheel dynamic response to road excitation during rolling has been simulated using finite element modelling in a graphical programming environment. The actual contact is an area not a single line and the contact edges are subject to continuous impacts during the rolling. The structural response to the impact generates structure borne noise as part of pollution to the environment. To reduce the wheel noise can be achieved by attenuating the intensity of structural vibration. The relationship between the noise generation energy of wheel and damping is investigated. It is proposed to reduce the noise by increasing the damping in the tyre structure. The effectiveness has been demonstrated by the simulation result.
\end{abstract}

\section{Introduction}

A major part of noise of fast travelling vehicle on road is generated from the tyre due to impact between the tyre contact area and road surface. The vehicle tyre noise has been drawn great attention as increasing number of vehicles is operating on the road and demand on environment quality is rising in recent decades. One of the rubber tyre functions is to isolate the vibration excitation caused by the road roughness for the rider. However, fast rolling wheel generates noise to all its surroundings through the air. Due to main target for tyre research and development have been the road gripping durability and safety, significant measures taken to reduce the noise has been limited so far.

Tyre dynamic modelling for the behaviour and its interaction with road surfaces have been made significant efforts [1-13]. The idea using damping material to absorb vibration and noise also have been proposed for a long time [14-18]. A typical existing product example includes that an acoustic damping sheet is formulated for maximum damping efficiency over a broad frequency and temperature range with easy peel and stick features. Tests show that the absorption can be from 13 $\mathrm{dB}$ to $42 \mathrm{~dB}$ from frequency $100 \mathrm{~Hz}$ to $5000 \mathrm{~Hz}$. The higher the frequency, the more effective. Therefore, to use damping material to reduce tyre rolling noise becomes a hope for road noise solution.

In this work, the tyre vibration reduced by damping material is simulated. It is shown that the more tyre vibrating energy can be dissipated in the damping, the more structure borne noise can be reduced. Furthermore, as an option, the damping material can be combined with a certain type of piezoelectric material, and the vibrating energy can be recovered at least partially and transferred into electricity used by sensors or other power needed devices. This paper will be focused on the simulation of vibrating wheel using finite element model in graphical dynamics environment, and how the vibrating energy is dissipated by increasing the damping in the tyre structure.

For better understanding of tyre wheel dynamic behaviour, displaying the dynamic characteristics is realised in MATLAB SIMULINK environment as this graphically presents the real-time dynamic behaviour of a wheel. This novel methodology has combined the merit of real-time simulation and straightforward finite element visual effect. The result is useful in wheel design including the selection of structure geometry and damping materials. 


\section{Dynamic Model and Impact Responses to Road Excitation}

The noise reduction is to be achieved by reducing the intensity of structural vibration generated from continuous impact by the road. A wheel with impact from road surface can be shown Fig. 1. Due to weight of vehicle, the wheel surrounded with a tyre is no longer round, and the contact of a wheel to the ground is no longer at only point $\mathrm{O}^{\prime}$ but along a flat line A-O-B.

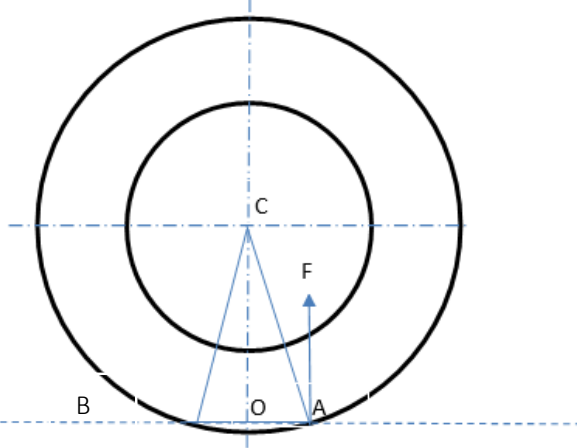

Fig. 1 Road impact or rolling wheel.

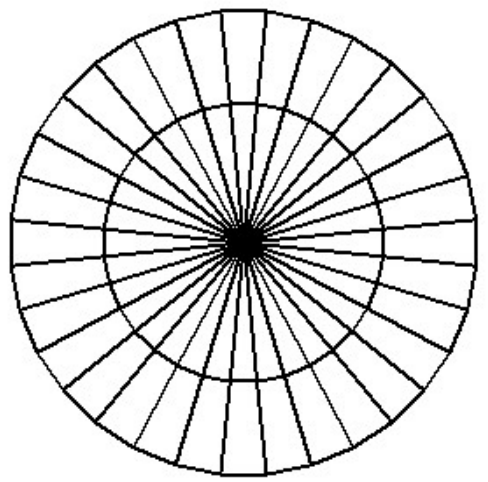

Fig. 2 Finite Element Wheel Model.

During fast rolling (assumed counter-clockwise), the velocity of contact A is significant, and the edge of contact receives an impact from the ground. This impact is continuously happening to the circumference of the tyre. In addition, the contact $B$ receives an impact due to sudden release of previously compressed rubber.

A finite element model of a tyred wheel using beam elements is assembled shown in Fig. 2. The inside circle and radial beams represent the metal rim, and the outer circumference and radial beams represent the rubber tyre. With $N$ degrees of freedom, the dynamics of the model is governed by the equation of motion $[19,20]$ :

$$
[m]\{\ddot{z}\}+[c]\{\dot{z}\}+[k]\{z\}=\{u(t)\}
$$

where, $[m]_{N \times N},[c]_{N \times N},[k]_{N \times N},\{z\}_{N \times 1},\{u(t)\}_{N \times 1}$ are the mass matrix, damping matrix, stiffness matrix, displacement vector and external force vector, respectively. For demonstrating the methodology only, the damping is assumed to be linear and viscous. The structural displacement response $\{z\}$ is caused by the external force from the road impact $\{u(t)\}$. For simulation, in the state space, the equation of motion Eq. (1) can be expressed as

$$
\begin{aligned}
& \{\dot{x}\}=[A]\{x\}+[B]\{u\} \\
& \{y\}=[C]\{x\}+[D]\{u\}
\end{aligned}
$$

where, the coefficient matrices are

$$
\{x\}=\left\{\begin{array}{l}
z \\
\dot{z}
\end{array}\right\}_{2 N \times 1}, \quad[A]=\left[\begin{array}{cc}
0 & I \\
-m^{-1} k & -m^{-1} c
\end{array}\right]_{2 N \times 2 N}, \quad[B]=\left[\begin{array}{c}
0 \\
-m^{-1}
\end{array}\right]_{2 N \times N},[C]=[I]_{2 N \times 2 N}, \quad[D]=[0]_{2 N \times N} .
$$

The external force $\{u(t)\}$ is the excitation from the road, equivalent to a circular forces acting in radial direction continuously along the circumference. For building the structural model, beam elements have been chosen to describe the wheel tyre and wheel metal rim with different mass, stiffness and damping parameters as in Fig. 2. During the rolling, the vibrating kinetic energy and potential energy in the tyre structure $E=\frac{1}{2}\{\dot{z}\}^{T}[m]\{\dot{z}\}+\frac{1}{2}\{z\}^{T}[k]\{z\}$ is to be damped. The linear and viscous damping force is $\left\{f_{d}\right\}=[c]\{\dot{z}\}$. Using damping work $W_{d}=\int\left\{f_{d}\right\}^{T} d\{z\}=\int\left\{f_{d}\right\}^{T}\{\dot{z}\} d t=\int\{\dot{z}\}^{T}[c]\{\dot{z}\} d t$, in the case that the system is subject to the impulse at 
$\mathrm{t}=0, E(0)=W_{d}$. i.e., the initial energy of the response to the impulse will be totally dissipated by the damping after a certain period of time. The structural borne noise is related to the total vibration intensity $I=\int\{\dot{z}\}^{T}\{\dot{z}\} d t$ over one whole wheel revolution [14]. The higher the damping, the quicker the damping absorbs, and the shorter there will be for generating noise by the vibrating structure.

\section{Simulation Model for Dynamic Responses}

MATLAB SIMULINK software is used for a real time graphical simulation for the wheel dynamics. The state space tyred wheel system is illustrated as in Fig. 3. The multiple inputs are the road impulses applied on the finite element nodes in the impact direction shown by the arrow in Fig. 1. Considering the relative motion, assuming the road is rotating relative to the wheel, the center of the wheel is regarded fixed.

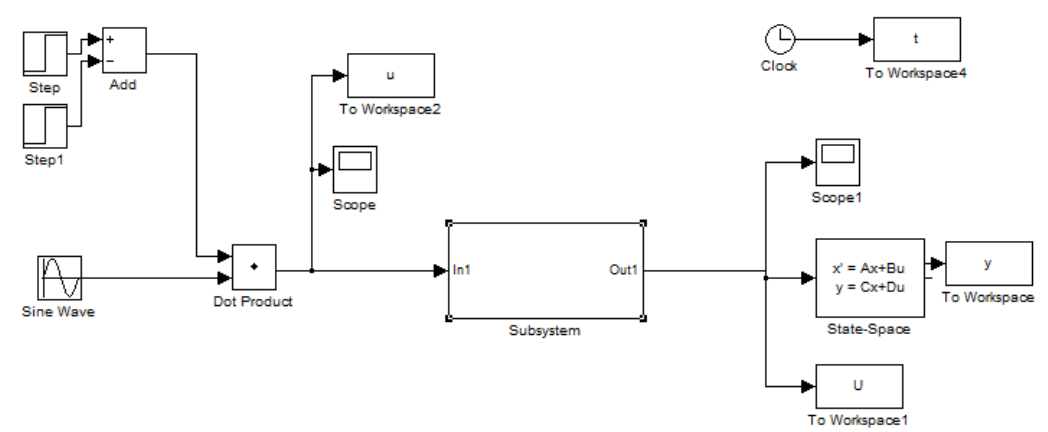

Fig. 3 The SIMULINK model for wheel dynamics.

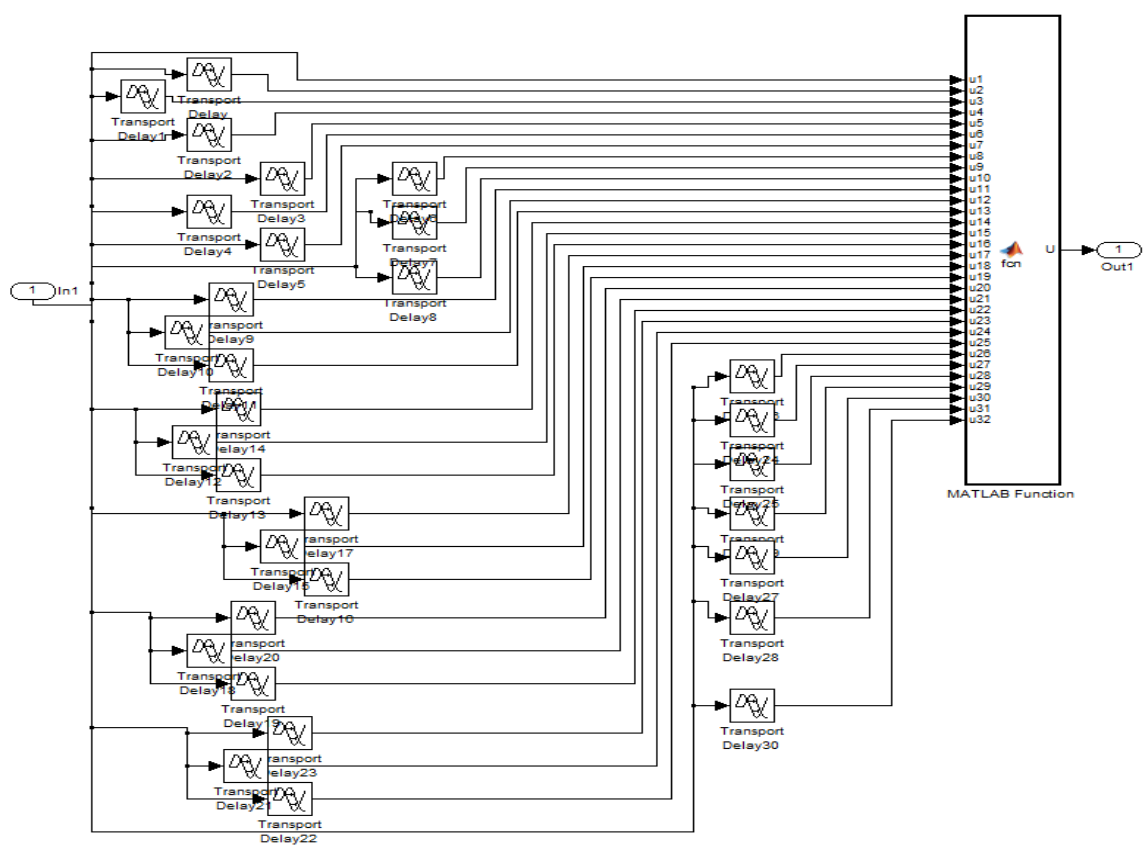

Fig. 4 The subsystem for applying impacts on wheel.

The continuous impact on the wheel during the rolling on road is simulated as a series of impulses with sequential time delays applied along the wheel circumference nodes as in Fig. 4. A MATLAB function is used to control the geometrical directions of the applied impulses. The key code of the function is as below:

function $\mathrm{U}=\mathrm{fcn}(\mathrm{u} 1, \mathrm{u} 2, \mathrm{u} 3, \mathrm{u} 4, \mathrm{u} 5, \mathrm{u} 6, \mathrm{u} 7, \mathrm{u} 8, \mathrm{u} 9, \mathrm{u} 10, \mathrm{u} 11, \mathrm{u} 12, \mathrm{u} 13, \mathrm{u} 14, \mathrm{u} 15, \mathrm{u} 16, \mathrm{u} 17, \mathrm{u} 18$, u19, u20, u21, u22, u23, u24, u25, u26, u27, u28, u29, u30, u31, u32) 
$\mathrm{N}=$ length(u1);U=zeros $(195, \mathrm{~N}) ; \mathrm{B}=2 *$ pi/64-pi/2; $\mathrm{U}(4)=\mathrm{u} 1 * \cos (\mathrm{B}) ; \mathrm{U}(5)=\mathrm{u} 1 * \sin (\mathrm{B})$;

$\mathrm{B}=\mathrm{B}+2 * \mathrm{pi} / 32 ; \quad \mathrm{U}(7)=\mathrm{u} 2 * \cos (\mathrm{B}) ; \mathrm{U}(8)=\mathrm{u} 2 * \sin (\mathrm{B}) ; \quad \ldots \quad \ldots ; \quad \mathrm{B}=\mathrm{B}+2 * \mathrm{pi} / 32 ; \quad \mathrm{U}(1)=\mathrm{u} 32 * \cos (\mathrm{B}) ;$ $\mathrm{U}(2)=\mathrm{u} 32 * \sin (\mathrm{B}) ; \mathrm{U}=-\mathrm{U}$;

\section{Dynamic Responses}

A complete set of impulses are applied to the wheel tyre along the circumference nodes. The first impulse and the subsequent ones over one revolution are shown in Fig. 5. The total structural vibration intensity $I$ varying with the damping factor is shown in Fig. 6, which decreases as damping increases. Therefore, the structural borne noise can be to be reduced by increasing the damping in the structure. Fig. 7 and 8 shows it takes longer time for lower damping oscillation to decay than higher damping. By increasing the damping, the displacement intensity is reduced as illustrated in Fig. 9. Each displacement curve is corresponding to a time instant. The displacements at equally spaced time instants form a deformation cloud.
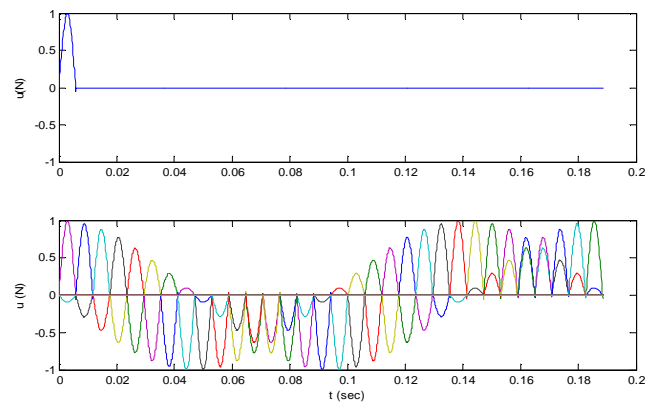

Fig. 5 Upper: first impulse. Lower: impulses along wheel circumference for one revolution.

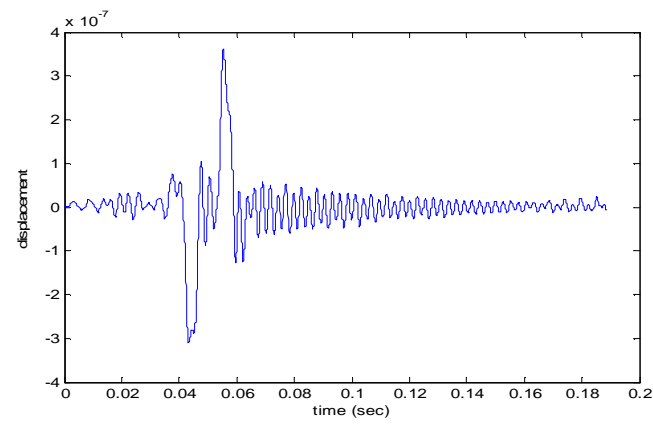

Fig. 7 The wheel response at contact node by single impact.

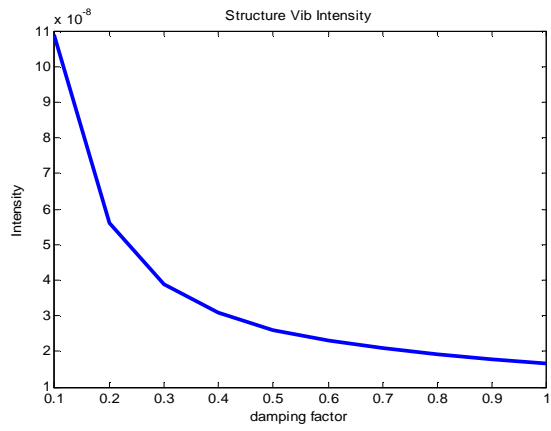

Fig. 6 Total structural vibration intensity.

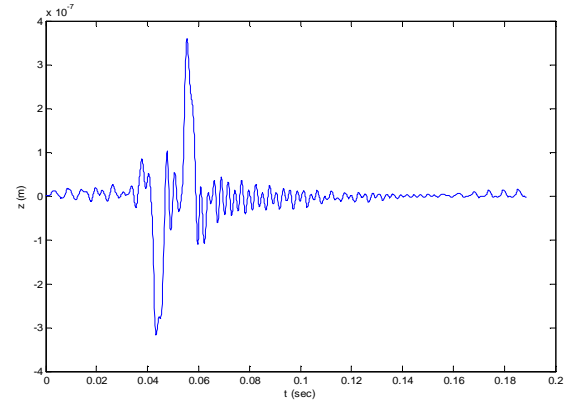

Fig. 8 The wheel response at contact node by single impact with higher damping.
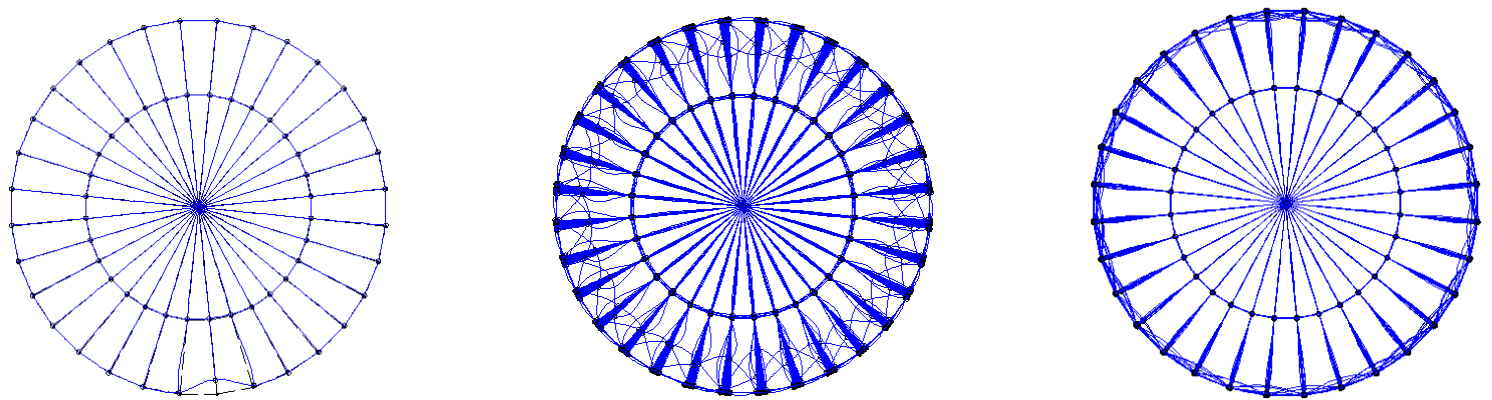

Fig. 9 Displacement instants on wheel from left to right: single impact response, one revolution responses and one revolution responses with higher damping. 


\section{Conclusion}

A finite element model is combined into the graphical dynamic simulation for visualizing vehicle wheel's response to road excitation. Real time dynamic behaviour of the wheel to continuous impacts from the road during rolling is displayed. The calculation result has indicated that the vibration which generates noise can be attenuated by increasing the damping in the wheel structure. Therefore, the structure borne noise can be reduced in favour of the passengers in the vehicle and residents close to highways. This author proposed modelling and simulation have improved the understanding of wheel dynamics and can be used for environment friendly wheel design and development.

\section{References}

[1] T. Sakata, H. Morimura, Effects of Tire Cavity Resonance on Vehicle Road Noise, Tire Sci. Tech. TSTCA 18(2) (1990) 68-79.

[2] E. J. Ni, D. S. Snyder, et al, Radiated Noise from Tire/Wheel Vibration, Tire Sci. Tech. TSTCA 25(1) (1997) 29-42.

[3] M. V. Blundell, The modelling and simulation of vehicle handling Part 3: tyre modelling. IMechE. Proceedings: Part K: J. Multi-body Dyn. 214 (2000) 1-32.

[4] K. Larrson, W. Kropp, A high-frequency three-dimensional tyre model based on two coupled elastic layers. J. Sound Vibr. 253(4) (2002) 889-908.

[5] W. Kropp, K. Larsson, F. Wullens, P. Andersson, F. X. Becot, The generation of tyre/road noise mechanisms and models, ICSV 10, Stockholm, 2003.

[6] Y. J. Kim, J. S. Bolton, Effects of rotation on the dynamics of a circular cylindrical shell with application to tire vibration, J. Sound Vibr. 275 (2004) 605-621.

[7] L. G. Hartleip, T. J. Roggenkamp, Case study - Experimental determination of airborne and structureborne road noise spectral content on passenger vehicles, SAE Noise and Vibration Conference 2005, Traverse City, USA, paper 2005-01-2522.

[8] H. B. Pacejka, Tyre And Vehicle Dynamics, $2^{\text {nd }}$ Edition, ELSEVIER 2006.

[9] M. V. Blundell, D. Harty, Intermediate tyre model for vehicle handling simulation. IMechE. Proceedings: Part K: J. Multi-body Dyn. 221(K1) (2006) 41-62.

[10] B. S. Kim, G. J. Kim, T. K. Lee, The identification of tyre induced vehicle interior noise, Appl. Acoust. 68(1) (2007) 134-156.

[11] P. Kindt, P. Sas, W. Desmet, Three-dimensional Ring Model for the Prediction of the Tyre Structural Dynamic Behaviour, Proc. ISMA2008, 4155-4170.

[12] Y. T. Wei, C. Oertel, Modelling Vibration and Impacting Behaviour of Tire by Absolute Finite Element Method, Tire Technology EXPO 2012, Cologn February 2012.

[13] H. Olsson, Tire force and moment modelling using FEA results, Tire Technology EXPO 2012, Cologn February 2012.

[14] M. P. Norton, Fundamentals of Noise and Vibration Analysis for Engineers, Cambridge University Press, 1989, ISBN: 0-521-34148-5.

[15] C. F. Beards, Structural Vibration Analysis and Damping, ARNOLD, 1996, ISBN: 0-340-64580-6.

[16] E. I. Rivin, Stiffness and Damping in Mechanical Design, Marcel Dekker, Inc. 1999, ISBN: $0-8247-1722-8$. 
[17] C. W. De Silva, Vibration Damping, Control, and Design, CRC Press, 2007. ISBN:1-4200-5321-3.

[18] D. Thorby, Structural Dynamics and Vibration in Practice - An Engineering Handbook, ELSEVIER, 2008, ISBN: 978-0-7506-8002-8.

[19] P. I. Kattan, Matlab Guide to Finite Elements An Interactive Approach, Springer 2002.

[20] A. J. M. Ferreira, MATLAB Codes for Finite Element Analysis- Solids and Structures, Springer 2009. ISBN 978-1-4020-9199-5. 